\title{
MODELO DE COMÉRCIO ELETRÔNICO E UM ESTUDO NO SETOR BANCÁRIO
}

\author{
Alberto Luiz Albertin \\ Professor do Departamento de Informática e Métodos Quantitativos da EAESP/FGV.
}

RESUMO

O ambiente empresarial, tanto em nível mundial como nacional, tem passado por profundas mudanças nos últimos anos, as quais têm sido consideradas diretamente relacionadas com a tecnologia de informação. Nesse novo ambiente, o comércio eletrônico é tido como uma das tendências emergentes com maior poder potencial de inovação nos processos de negócio nos vários setores econômicos. No caso do setor bancário, as aplicações de comércio eletrônico ganham uma dimensão significativa, devido às suas características e às de seus produtos, serviços e clientes. Este artigo tem por objetivo apresentar o Modelo Integrado de Comércio Eletrônico e os principais resultados da pesquisa realizada no setor bancário, enfatizando as tendências dessa aplicação de tecnologia de informação e o relacionamento com algumas das principais características do ambiente empresarial atual.

\section{ABSTRACT}

The new business environment, national as well as international, has deeply changed, and the information technology has a special value on the changes. At this new environment, the electronic commerce is considered a powerful emergent trend for business processes innovation. The electronic commerce applications signify an important impact for the banking sector, giving the characteristics of

the sector and its products, services and clients. This article presents the Electronic Commerce Integrated Model and the main results of the research done at the banking sector, stressing the trends of this information technology application and the relationship with some of the most important issues of the business environment.

\section{PALAVRAS-CHAVE}

Comércio eletrônico, tecnologia de informação, setor bancário.

KEY WORDS

Electronic commerce, information technology, banking sector. 


\section{INTRODUÇÃO}

O futuro é a Tecnologia de Informação (TI), uma poderosa ferramenta empresarial que altera as bases da competitividade e as estratégias empresariais. As organizações passaram a realizar seus planejamentos e a criar suas estratégias voltadas para o futuro, tendo como uma de suas principais bases a TI, devido a seus impactos sociais e empresariais.

O ambiente empresarial, tanto em nível mundial como nacional, tem passado por profundas mudanças nos últimos anos, as quais têm sido consideradas diretamente relacionadas com a TI. Essa relação engloba desde o surgimento de novas tecnologias, ou novas aplicações, para atender às necessidades do novo ambiente até o aparecimento de novas oportunidades empresariais criadas pelas novas tecnologias ou por novas formas de sua aplicação.

Atualmente, algumas das características do novo ambiente empresarial, tais como globalização, integração interna e externa das organizações, entre outras, têm confirmado as tendências da criação e utilização de mercado e comércio eletrônicos, os quais já são considerados uma realidade.

Nesse novo ambiente empresarial, o setor bancário continua sendo considerado um dos que mais investem em Tecnologia de Informação, tendo seus produtos e serviços fundamentalmente apoiados nessa tecnologia. Esse setor participa ativamente nas operações e nos processos dos demais setores, sendo também influenciado pelas transformações externas.

Assim, seja pelo seu novo ambiente ou por força dos demais setores, o setor bancário é um dos mais afetados pela nova realidade de mercado e comércio eletrônicos. Essa situação tem exigido dos bancos um grande esforço para a assimilação e a utilização das tecnologias de informação referentes a comércio eletrônico, na sua operacionalização e na sua estratégia competitiva.

Este artigo apresenta o Modelo Integrado de Comércio Eletrônico e as principais definições e contribuições do projeto de pesquisa de comércio eletrônico no setor bancário brasileiro realizado por Albertin (1997), que teve por objetivo identificar a situação atual da utilização das aplicações de comércio eletrônico nesse setor, mais especificamente sob a visão administrativa, ou seja, focalizando como estão sendo considerados os vários aspectos gerenciais e estratégicos da utilização de comércio eletrônico pelo setor, bem como seu valor, benefícios estratégicos e contribuições para o sucesso das instituições.

\section{COMÉRCIO ELETRÔNICO}

O comércio eletrônico (CE) é a realização de toda a cadeia de valor dos processos de negócio num ambiente eletrônico, por meio da aplicação intensiva das tecnologias de comunicação e de informação, atendendo aos objetivos de negócio. Os processos podem ser realizados de forma completa ou parcial, incluindo as transações negócio-a-negócio, negócio-aconsumidor e consumidor-a-negócio.

O CE, conforme a definição de Cameron (1997), inclui qualquer negócio transacionado eletronicamente, em que essas transações ocorrem entre dois parceiros de negócio ou entre um negócio e seus clientes.

Segundo Kalakota e Whinston (1997), o CE pode ser definido como a compra e a venda de informações, produtos e serviços por meio de redes de computadores. Bloch, Pigneur e Segev
O comércio eletrônico é a realização de toda a cadeia de valor dos processos de negócio num

\section{ambiente} eletrônico. (1996) estenderam essa definição, incluindo que o CE é o suporte para qualquer tipo de transações de negócio sobre uma infra-estrutura digital.

Cabe mencionar o argumento de Connoly (1997), segundo o qual os estudos de CE geralmente são fortemente focados em segurança, criptografia, moedas e pagamentos eletrônicos. No entanto, comércio é mais do que apenas a troca de dinheiro. Ele inclui pesquisa, desenvolvimento, marketing, propaganda, negociação, vendas e suporte, citando somente alguns aspectos. Considera-se que uma plataforma bemsucedida de CE irá melhorar o desempenho de todas essas atividades.

Kalakota e Whinston (1996) consideram que o ambiente tradicional de negócio está mudando rapidamente, com os consumidores e os negócios procurando flexibilidade para mudar os parceiros de negócio, plataformas, carreiras e redes. Essa mudança inclui estabelecer conexões eletrônicas com clientes, fornecedores, distribuidores, grupos de indústria e mesmo com concorrentes para incrementar a eficiência das comunicações de negócio, expandir a participação no mercado e manter a viabilidade de longo prazo no ambiente de negócio de hoje. Em outras palavras, a mudança está diretamente ligada ao CE. 


\section{MODELO INTEGRADO DE COMÉRCIO ELETRÔNICO}

O Modelo Integrado de Comércio Eletrônico, apresentado na Figura 1 e originalmente definido por Albertin (1997), enfatiza as várias camadas que compõem o próprio ambiente do CE e sua integração com o ambiente empresarial. Esse modelo tem sido utilizado com sucesso para o estudo da utilização do CE, enfatizando seus aspectos, valor, benefícios estratégicos e contribuições para o sucesso das organizações.

\section{Figura 1 - Modelo Integrado de Comércio Eletrônico}

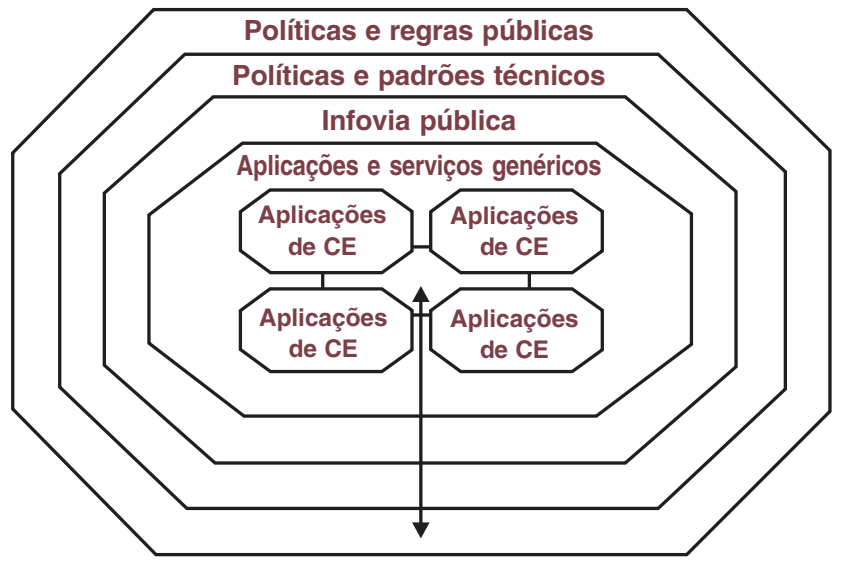

Fonte: Albertin (1997).

O modelo utiliza o conceito de camadas, e não de pilares, por considerar que ele é utilizado num contexto. Portanto, ele afeta e é afetado pelos componentes desse ambiente, não sendo apenas apoiado em alguns deles. As camadas que compõem o modelo são:

Políticas e regras públicas: estão relacionadas com os aspectos legais, de regulamentação dos setores e mercados, das normas oficiais etc.

Políticas e padrões técnicos: estão relacionados com os aspectos de padronização para a compatibilização dos componentes do ambiente técnico, políticas de tratamento e comunicação de informações, interfaces etc.

Infovia pública: é a rede formada tanto pela rede mundial Internet como pelos serviços on-line que tenham ligações com esta, sendo que a ênfase é no acesso livre e de baixo custo e na integração entre os vários ambientes sem nenhuma restrição, incluindo desde os terminais mais simples de acesso até meios de comunicação mais sofisticados para grandes volumes de informação.
Aplicações e serviços genéricos: são aqueles oferecidos pelo ambiente, por meio de seus provedores, serviços on-line e fornecedores, disponíveis a todos. Correio eletrônico, transferência de arquivos, salas virtuais, algoritmos, softwares de criptografia etc. podem ser citados como exemplos de aplicações e serviços genéricos.

Aplicações de comércio eletrônico: são aquelas desenvolvidas com base nas camadas anteriores e que atendem às necessidades de uma organização ou grupo delas, tais como home banking, vídeo sob demanda, shopping centers virtuais etc.

A seta de duas direções une as várias camadas entre si e determina a influência que cada uma exerce sobre as demais, bem como a influência recebida. Essa influência inclui que uma camada, por um lado, está limitada pelas restrições impostas pelas demais, assim como limita as demais camadas. Por outro lado, uma camada garante que as demais possam existir e fornece a base e os recursos para que possam se desenvolver. Finalmente, cada camada tende a exigir a adequação e a evolução das demais de acordo com sua própria evolução, suas necessidades e as oportunidades que oferecem ao ambiente externo.

\section{DIMENSÕES DE ANÁLISE DO COMÉRCIO ELETRÔNICO}

A análise do CE deve ter como base principal duas dimensões: os aspectos a serem considerados na utilização do $\mathrm{CE}$ e as contribuições que a utilização do CE oferece às organizações.

Albertin (1998) apresentou um conjunto de aspectos e benefícios a serem considerados nos estudos e nas aplicações do CE. Com base nesse trabalho, foi elaborado um novo conjunto de aspectos do CE.

O conjunto de contribuições do CE foi elaborado considerando o seu papel no sucesso das empresas que se defrontam com mudanças na economia e no mercado, os benefícios estratégicos que ele oferece na dinâmica e na estratégia competitiva das organizações e o valor adicionado pelo $\mathrm{CE}$ aos seus negócios. O Quadro 1 apresenta os aspectos e as contribuições do CE classificados por categorias.

\section{ASPECTOS DO COMÉRCIO ELETRÔNICO}

Os aspectos do CE podem ser entendidos da seguinte maneira:

\section{Adoção}

A chave para o sucesso do sistema de CE para os clientes certamente é uma grande adoção desses ti- 
pos de tecnologias por parte deles. Além dos problemas de resistência, aprendizagem e falta de infraestrutura, outro desafio é solucionar o problema do tipo ovo e galinha: por um lado, a adoção é baixa porque existem poucas organizações participando e, por outro, as organizações não participam porque a adoção é baixa.

\section{Relacionamento}

$\mathrm{O}$ relacionamento com clientes e fornecedores tende a ser significativamente alterado com a adoção intensa do CE. Os motivos são variados: eliminação de intermediários, diminuição da interação face a face, integração eletrônica disponível e facilmente acessível, maior informação sobre o cliente, entre outros.

\section{Adequação}

Os produtos e serviços atuais nem sempre são adequados às novas formas de divulgação, venda e distribuição possibilitadas pelo $\mathrm{CE}$ tanto na forma como no conteúdo. O CE oferece, contudo, novas e revolucionárias maneiras de se realizar os processos de negócio.

\section{Estratégia}

O CE oferece uma grande quantidade de novas oportunidades para as organizações, exigindo que elas alterem significativamente suas estratégias, sob a pena de ser definitivamente superadas pelos demais participantes, sejam eles do próprio setor ou não.

\section{Comprometimento organizacional}

O comprometimento organizacional é imprescindível para a utilização com sucesso de um sistema de CE. Esse comprometimento inclui significativos investimentos para criação e manutenção dos sistemas, administração de mudanças organizacionais profundas, gerenciamento de riscos etc.

\section{Privacidade e segurança}

Uma fonte potencial de problemas é a preocupação dos clientes com privacidade e segurança, o que poderia levar a uma forte reação contra os fornecedores que utilizam tais sistemas ou simplesmente a não-utilização desses sistemas por parte dos clientes.

\section{Sistemas eletrônicos de pagamento}

As transações eletrônicas de negócio somente podem ter sucesso se as trocas financeiras entre compradores e vendedores puderem acontecer em um ambiente simples, universalmente aceito, seguro e barato. Os tipos de sistemas eletrônicos de pagamento são: dinheiro eletrônico ( $e$-cash), cheque eletrônico $(e-$ check), cartões inteligentes (smart cards), cartões de crédito e cartões de débito.

\section{Aspectos legais}

Os aspectos legais, como a regulamentação de um setor, podem restringir a aplicação do $\mathrm{CE}$, seja pela obrigatoriedade de documentos e da presença física, seja pela não-consideração da nova forma de negócio possibilitada pelo $\mathrm{CE}$ e de seus processos.

\section{Quadro 1 - Aspectos e contribuições do CE}

\begin{tabular}{|c|c|c|}
\hline Categoria & Aspecto & Contribuição \\
\hline $\begin{array}{l}\text { Clientes e } \\
\text { fornecedores }\end{array}$ & $\begin{array}{l}\text { - Adoção } \\
\text { - Relacionamento }\end{array}$ & - Relacionamento \\
\hline $\begin{array}{l}\text { Produtos e } \\
\text { serviços }\end{array}$ & - Adequação & $\begin{array}{l}\text { - Customização em massa } \\
\text { - Inovação de produtos } \\
\text { - Novos canais de venda/distribuição } \\
\text { - Promoção de produtos }\end{array}$ \\
\hline Organização & $\begin{array}{l}\text { - Estratégia } \\
\text { - Comprometimento organizacional }\end{array}$ & $\begin{array}{l}\text { - Novas oportunidades de negócio } \\
\text { - Estratégia competitiva } \\
\text { - Economia direta }\end{array}$ \\
\hline Tecnologia & $\begin{array}{l}\text { - Privacidade e segurança } \\
\text { - Sistemas eletrônicos de pagamento } \\
\text { - Aspectos legais } \\
\text { - Aspectos de implementação }\end{array}$ & - Infra-estrutura pública \\
\hline
\end{tabular}




\section{Aspectos de implementação}

A maioria dos envolvidos com tecnologia acredita que uma tecnologia sozinha não resolve aspectos nem cria vantagens, mesmo as do CE. A tecnologia precisa ser integrada a uma organização, com os aspectos de gerenciamento de mudanças relacionados com a resistência das pessoas a novos conceitos e idéias.

O Modelo Integrado de Comércio Eletrônico enfatiza as várias camadas que compõem

o próprio ambiente do CE e sua integração com 0 ambiente empresarial.

\section{CONTRIBUIÇÕES DO COMÉRCIO ELETRÔNICO}

As contribuições do CE são as seguintes:

\section{Relacionamento}

A visão tradicional de uma empresa com fronteiras claras, relações limitadas com parceiros e mercados estáveis está evoluindo. Atualmente, as tecnologias podem alavancar um redesenho das relações interorganizacionais, permitindo às companhias:

- melhorar a coleta de informações sobre o seu ambiente além da fronteira;

- estabelecer parcerias baseadas em meios eletrônicos com seus clientes e fornecedores;

- compartilhar plataformas e mercados eletrônicos com seus concorrentes.

As empresas se comunicam com seus clientes por várias mídias. Por muitos anos, as tecnologias vêm alterando profundamente a visão tradicional de mídia de marketing, compra e venda. Os ambientes intermediados por computadores, como a Internet, permitem uma outra maneira de alcançar os consumidores e incentivam compradores e vendedores a incrementar sua utilização por permitir:

- melhoria na comunicação com seus clientes;

- mais eficiência nas relações de vendas com clientes;

- mais atratividade nos seus mercados.

\section{Inovação e customização de produtos}

A flexibilidade e o poder de resposta são as novas regras no ambiente empresarial atual permitidas pelo CE. A estratégia de produzir e vender da era industrial foi substituída pela estratégia de sen- tir as mudanças das necessidades e particularidades dos clientes e responder rapidamente.

A natureza baseada em informação dos processos de CE permite que os novos produtos a serem criados ou os produtos existentes sejam customizados de maneiras inovadoras. Uma das oportunidades para a customização em massa é ter o cliente tomando parte do próprio projeto do produto ou serviço.

Além disso, com base na sua natureza instantânea, os sistemas de CE permitem reduzir o ciclo de vida de produção e entrega de produtos e serviços aos clientes.

\section{Novos canais de venda/distribuição}

Devido ao seu alcance direto e à sua natureza bidirecional na comunicação de informações, os sistemas de CE representam um novo canal de vendas e distribuição para os produtos, existentes ou novos.

\section{Promoção de produtos}

Por meio de um contato direto, rico em informações e interativo com os clientes, o CE pode melhorar a promoção dos produtos e serviços, permitindo ao cliente inclusive "navegar" neles.

\section{Novas oportunidades de negócio}

Alterando as estruturas dos setores, os sistemas de CE permitem o surgimento de novos modelos de negócios, baseados na ampla disponibilidade de informações e em sua distribuição direta aos clientes e fornecedores.

\section{Estratégia competitiva}

O CE pode:

- proporcionar vantagens de custos;

- permitir a diferenciação de seus produtos e serviços;

- possibilitar melhor relacionamento com os clientes;

- permitir a entrada mais fácil em alguns mercados;

- possibilitar o estabelecimento de barreiras de entrada;

- auxiliar a introdução de produtos substitutos;

- facilitar a eliminação de intermediários;

- facilitar o surgimento de novos intermediários que adicionem valor por meio de informação;

- permitir novas estratégias competitivas com o uso de sua tecnologia.

\section{Economia direta}

O CE pode reduzir significativamente os custos de comercialização, distribuição e serviços a clientes com a utilização de uma infra-estrutura digital pública e compartilhada, tal como a Internet, em vez do uso de uma infra-estrutura própria. 


\section{Infra-estrutura pública}

A criação e a utilização de uma infra-estrutura pública, que seja composta de equipamentos de acesso, estruturas de acesso local e redes globais de informações, são formas de garantir o fácil e livre acesso ao ambiente digital do $\mathrm{CE}$ a um custo não proibitivo.

\section{SETOR BANCÁRIO}

A TI é considerada fundamental para o setor bancário, tanto em nível operacional como estratégico. As razões para essa importância residem nas características do setor.

Conforme definido por Crane e Bodie (1996), a indústria de serviços financeiros está se transformando de uma maneira imprevisível e, às vezes, contraditória. Uma das forças que têm acelerado essas mudanças é a nova tecnologia de informação.

A TI é vista como uma das maiores e mais poderosas influências a serem consideradas no planejamento das instituições financeiras. Segundo Baldwin (1991), o sistema bancário, sem dúvida, está passando por uma reestruturação radical. As diretrizes fundamentais da mudança são tecnológicas e irreversíveis. As modernas tecnologias de informação, comunicação e avaliação permitem uma qualidade mais alta em vários aspectos bancários.

Conforme observado por Albertin (1993), no estudo de fatores críticos de sucesso da administração de TI do setor bancário nacional, as maiores instituições bancárias brasileiras têm utilizado largamente a TI para interligar todas as suas agências em nível nacional, processar um número muito grande de transações e atender a uma quantidade de clientes dentro e fora das agências de forma rápida, segura e, muitas vezes, personalizada.

Apte et al. (1990) argumentam que o setor bancário tem passado por um período de turbulência nos últimos anos e que essa situação deve continuar nos próximos anos. As maiores alterações que têm afetado o setor bancário estão relacionadas com a regulamentação governamental, as mudanças tecnológicas e as preferências dos consumidores.

\section{O COMÉRCIO ELETRÔNICO E OS BANCOS}

O papel do CE é multifacetado para bancos, afetados pelas mudanças na tecnologia, pela rápida desregulamentação, pelo surgimento de novas instituições e pela reestruturação básica da economia. Dadas essas mudanças ambientais, os bancos estão reavaliando suas estruturas de custos e de lucro. Muitos bancos acreditam que, para ser lucrativos, precisam reduzir suas despesas operacionais e manter um controle rígido de custo. Essa filosofia é evidente nas muitas fusões e aquisições ocorridas no setor bancário.

A tecnologia está permitindo o desenvolvimento de novos produtos e serviços e mudando a interação entre os bancos e os consumidores. Em particular, as inovações tecnológicas têm viabilizado as seguintes capacidades:

- entrega on-line de brochuras do banco e informações de marketing;

- acesso eletrônico a extratos bancários;

- habilidade de solicitar a transferência de fundos entre contas;

- pagamento e apresentação eletrônicos de contas;

- habilidade de utilizar múltiplos produtos de software financeiro com memória (eliminando a necessidade de realimentar os mesmos dados);

- pagamentos on-line (cartões de crédito criptografados para a transferência de instruções de pagamento entre vendedores, bancos e clientes);

- micropagamentos
A análise do $\mathrm{CE}$ deve ter como base principal duas dimensões: os

aspectos a serem considerados na utilização do CE e as contribuições que a utilização do CE oferece às organizações. (transações de centavos utilizando dinheiro eletrônico ou cheques eletrônicos).

Essas capacidades on-line aumentam as facilidades e a velocidade dos bancos de varejo.

\section{ESTUDO NO SETOR BANCÁRIO}

O estudo do CE no setor bancário foi realizado pela metodologia de pesquisa de estudos de múltiplos casos e descrito de forma completa por Albertin (1997). As abordagens relatadas anteriormente, aspectos e contribuições, foram utilizadas como quadro de referência para este estudo, para o qual foi solicitada aos bancos estudados uma avaliação para cada uma das aplicações de CE.

Os casos estudados são um subconjunto das instituições bancárias privadas nacionais. A escolha desse setor baseou-se na consideração aceita de que as instituições bancárias são as que mais se apóiam em TI e que, além do alto investimento necessário, devem sem- 
pre despender razoável esforço organizacional para a assimilação e a utilização das novas tecnologias de informação. Essas organizações trabalham com informações, e a TI é parte integrante da maioria de seus produtos e serviços, o que deve acontecer também com as aplicações de CE. Outra consideração é que as mudanças econômicas e de mercado têm afetado de maneira acentuada esse setor, exigindo rápidas adaptações nos seus processos e procedimentos; um dos aspectos dessas mudanças são os novos sistemas eletrônicos de pagamento e a

A principal aplicações atuais em TI tradicional para as de TI/CE pode ser resumida na utilização das várias camadas apresentadas no Modelo Integrado de Comércio Eletrônico. diferença entre as concorrência no setor.

A escolha dos casos baseou-se também no fato de que as maiores instituições bancárias, em nível de patrimônio líquido, número de clientes, volume de depósito à vista e número de agências, precisam utilizar largamente a TI para interligar todas as suas agências em nível nacional, processar um número muito grande de transações e atender a uma grande quantidade de clientes dentro e fora das agências de uma forma rápida, segura e, muitas vezes, personalizada. Os casos são todos do setor privado, têm perfis de clientes similares e agências distribuídas pelo território nacional. Esse cuidado foi tomado para garantir a aplicação da lógica de réplica literal.

Os bancos que serviram de casos estão entre os maiores do setor bancário privado brasileiro e são responsáveis por mais de $15 \%$ do ativo total do setor, mais de $30 \%$ do depósito à vista, mais de $25 \%$ de patrimônio líquido e mais de 3.500 agências no país, conforme dados de 1996.

Os bancos geralmente utilizam a TI num ambiente estratégico. Considera-se ainda que, pelo tamanho das organizações envolvidas e pela complexidade do mercado nacional, sua utilização de TI deve ser, e é, também complexa.

Dessa forma, as utilizações, presentes e futuras, bem como os esforços organizacionais, são similares e complementares, cobrindo de forma bastante satisfatória uma possível relação entre os aspectos e contribuições para o sucesso do CE no setor bancário.

\section{O COMÉRCIO ELETRÔNICO E O SETOR BANCÁRIO}

Atualmente, as principais aplicações de TI de CE (TI/CE) a serem implementadas ou a terem sua utilização ampliada pelos bancos brasileiros obedecem à seguinte priorização:

1. Home banking (HB);

2. DOC eletrônico (DE);

3. Office banking (OB);

4. EDI;

5. Smart card (SC);

6. ATM;

7. E-cash;

8. E-check;

9. TV a cabo (TV).

A principal diferença entre as aplicações atuais em TI tradicional para as de TI/CE pode ser resumida na utilização das várias camadas apresentadas no Modelo Integrado de Comércio Eletrônico.

As aplicações de home banking em TI/CE, implementadas ou em teste, são amplamente similares àquelas desenvolvidas e implementadas em TI tradicional, que já estão em uso há bastante tempo. Os bancos têm, atualmente, incluído poucas funcionalidades que possam ser consideradas realmente novas.

$\mathrm{O}$ mesmo acontece com as aplicações de office banking dos casos estudados. No que se refere a essa aplicação, cabe mencionar que as maiores diferenças estão nas estratégias dos bancos em relação ao serviço em si.

A aplicação de EDI não tem a mesma prioridade que as aplicações de home banking e de office banking devido ao tipo de produtos e serviços e ao perfil dos clientes dos bancos estudados. No entanto, os bancos têm estudado e realizado esforços para iniciar a utilização de EDI na Internet, o que demonstra uma disposição de explorar mais essa aplicação, no segmento de negócio-a-negócio.

A Figura 2 apresenta a relação entre as contribuições de negócio-a-negócio e as de negócio-a-consumidor, em que é possível confirmar que as aplicações de TI/CE estão mais voltadas para o consumidor do que para o ambiente de negócio-a-negócio e que, nessa dimensão, as diferenças entre elas são mais expressivas.

A aplicação de TV a cabo deve passar a oferecer um número maior de informações aos clientes dos bancos, continuando a ser unidirecional e não interativa ainda por algum tempo. Essa situação deve-se principalmente a limitações tecnológicas das próprias empresas de TV a cabo atuais, ou seja, os bancos dependem da disponibilização dessa tecnologia por essas empresas. 
As aplicações de smart card têm seus modelos fortemente baseados no modelo de cartão de crédito, afiliação de estabelecimento e soluções proprietárias. Atualmente, os bancos utilizam infra-estrutura própria ou de terceiros, basicamente de algum participante do ambiente de cartões de crédito. Os bancos não têm, no momento do estudo de caso, uma previsão da implementação de smart card em grande escala e muito menos da utilização de modelos abertos e não proprietários.

As aplicações de ATM na TI/CE ainda são pou-

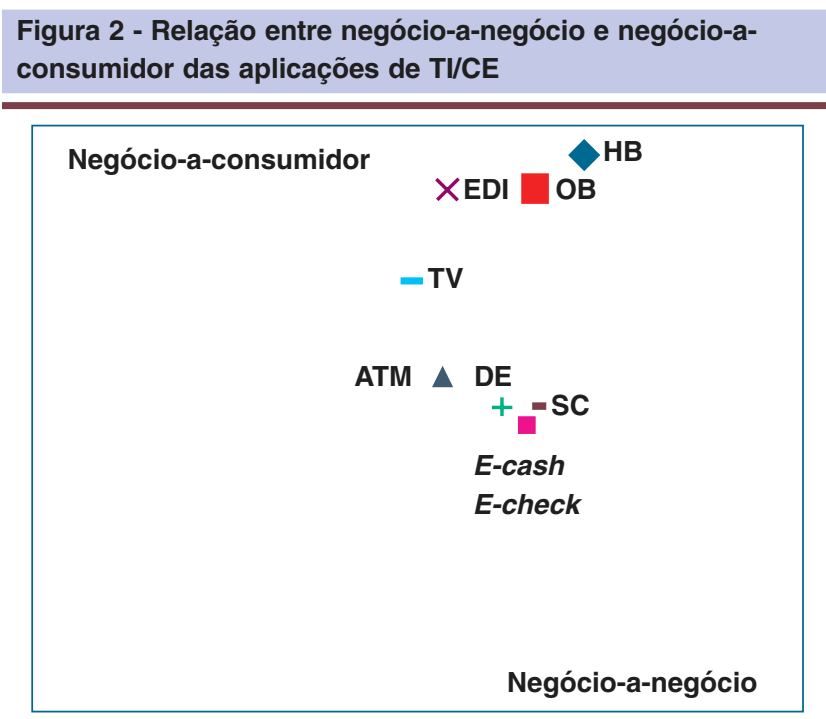

Fonte: Albertin (1997). co consideradas no planejamento dos bancos, seja para a conexão com outras redes, seja para atendimento de clientes de outros bancos ou oferta de produtos não bancários, apesar de ser reconhecido um potencial ainda pouco explorado e apesar da utilização por clientes de alguns bancos de outro país. As redes próprias de ATM são consideradas de alto valor estratégico, devendo permanecer assim ainda por bastante tempo, limitando as considerações sobre conexões e novas formas de utilização.

As aplicações de $e$-cash e de $e$-check têm sido objeto de estudos e de algumas discussões internas, porém, apesar de serem consideradas de grande potencial estratégico, não há nenhuma previsão para sua utilização.

A aplicação de DOC eletrônico ainda apresenta algumas dúvidas de conceituação, permitindo que um dos casos considere que a utiliza enquanto o outro não. A sua utilização aponta para a criação de câmaras automáticas e eletrônicas de compensação e para a discussão de modelos abertos.

O Quadro 2 apresenta o resumo das avaliações dos aspectos das aplicações de TI/CE, relacionando somente aquelas com melhor avaliação para cada um dos aspectos.

As aplicações de home banking, office banking e EDI são as que receberam maiores avaliações em relação aos aspectos de CE, com exceção dos aspectos de implementação e legais. Por outro lado, as aplicações

Quadro 2 - Avaliação dos aspectos das aplicações de TI/CE

\begin{tabular}{|c|c|c|}
\hline $\begin{array}{l}\text { Adoção } \\
\text { Home banking } \\
\text { Office banking } \\
\text { ATM } \\
\text { DOC eletrônico }\end{array}$ & $\begin{array}{l}\text { Relacionamento } \\
\text { Home banking } \\
\text { Office banking } \\
\text { EDI }\end{array}$ & $\begin{array}{l}\text { Adequação } \\
\text { Home banking } \\
\text { Office banking }\end{array}$ \\
\hline $\begin{array}{c}\text { Estratégia } \\
\text { Home banking }\end{array}$ & $\begin{array}{l}\text { Comprometimento organizacional } \\
\qquad \begin{array}{c}\text { Home banking } \\
\text { Office banking } \\
\text { EDI } \\
\text { Smart card }\end{array}\end{array}$ & $\begin{array}{l}\text { Privacidade e segurança } \\
\text { Home banking } \\
\text { Office banking } \\
\text { EDI } \\
\text { Smart card }\end{array}$ \\
\hline $\begin{array}{l}\text { Sistemas eletrônicos de pagamento } \\
\text { Home banking } \\
\text { Office banking } \\
\text { EDI } \\
\text { DOC eletrônico }\end{array}$ & $\begin{array}{l}\text { Aspectos legais } \\
\text { E-cash } \\
\text { E-check } \\
\text { DOC eletrônico } \\
\text { Smart card }\end{array}$ & $\begin{array}{c}\text { Aspectos de implementação } \\
\text { E-cash } \\
\text { E-check } \\
\text { Smart card }\end{array}$ \\
\hline
\end{tabular}

Fonte: Adaptado de Albertin (1997). 
de $e$-cash e $e$-check receberam maiores avaliações justamente para esses aspectos.

A adoção das novas aplicações de TI/CE não é considerada como limitada ou restrita, uma vez que elas guardam muita similaridade com as aplicações existentes, sendo facilitada pela familiaridade e experiência que os clientes possuem. Além disso, o número de clientes que já possuem conhecimento e recursos necessários para a utilização dessas tecnologias é significativo. Os bancos consideram que, em curto prazo, o terminal doméstico continuará a ser os microcomputadores.

Uma das formas de incentivo à adoção dessas aplicações é a não-cobrança de tarifas. Os bancos, porém, têm em seus planos iniciar a cobrança em curto ou, no máximo, em médio prazo.

Os bancos prevêem que as aplicações de TI/CE serão adotadas por uma quantidade de clientes e em um volume de transações que justifiquem os investimentos que estão sendo realizados. As aplicações de TI tradicional e o atendimento pessoal nas agências continuarão existindo, seja por motivos culturais dos clientes, seja por modelo de negócio. Em outras palavras, não haverá substituição completa, mas sim complementação e agregação de novos canais e novos produtos.

Os bancos, desde alguns anos, têm associado à sua imagem corporativa uma intensa utilização de TI, incluindo pioneirismo, redução de custo, agilidade, modernidade, redução de distâncias etc. As aplicações de TI/CE têm colaborado nessa iniciativa e têm sido utilizadas como arma estratégica. Essa situação tem levado alguns bancos a divulgar alguns de seus planos de forma bastante ampla e outros a ser bastante atentos ao sigilo dos seus planos.

$\mathrm{O}$ apoio da alta gerência ao desenvolvimento e à utilização das aplicações de TI/CE é bastante significativo na forma como está sendo realizado atualmente. Alguns dos indícios desse apoio são os investimentos realizados, a criação de áreas específicas nos organogramas etc. Nota-se ainda alguma resistência interna de outras áreas, principalmente em relação ao crescimento da importância da TI/CE em relação à TI tradicional e da sua utilização para a mudança de processos de negócio.

Os aspectos legais, ainda que não estejam totalmente adequados à nova realidade tecnológica, são considerados com grande impacto para aquelas aplicações de TI/CE que têm suas utilizações planejadas em longo prazo, principalmente as de $e$-cash e e-check. As aplicações que estão sendo atual e mais intensamente utilizadas já estão adequadas às regras legais.

A aplicação de TI/CE considerada a mais fortemente relacionada com os sistemas eletrônicos de pagamento é a de home banking, seguida das de office banking, EDI e DOC eletrônico. Entretanto essas aplicações, em curto e médio prazos, devem ser utilizadas somente para pagamentos que tenham um documento físico correspondente no mundo físico, como ficha de compensação, ou que sejam entre clientes do próprio banco. Os pagamentos eletrônicos para clientes de outros bancos são considerados ainda sem grande valor estratégico e com riscos de segurança.

Os bancos não consideram que os aspectos de segurança e privacidade tenham grande influência nessa adoção, uma vez que eles são relativamente pouco valorizados pelos clientes e devido ao fato de os pagamentos eletrônicos ainda estarem fortemente relacionados a cartão de crédito.

A Figura 3 apresenta a relação entre os valores e os benefícios atribuídos pelos casos estudados.

As aplicações de home banking, office banking e EDI são aquelas que receberam maiores avaliações em relação aos valores e benefícios que oferecem aos bancos, confirmando e sendo coerentes com a priorização de implementação.

Os bancos consideram que as aplicações de TI/CE que devem afetar mais o relacionamento com os clientes são as de home banking, office banking e EDI, uma vez que essas aplicações têm o potencial de mudar significativamente os processos de negociação entre os bancos e seus clientes. Por outro lado, essas aplicações são as que devem contribuir de forma mais significativa para a obtenção de informações sobre os clientes, podendo facilitar a customização dos produtos e serviços bancários e, assim, melhorar o relacionamento com os clientes.

Figura 3 - Relação entre valor de negócio e benefícios estratégicos das aplicações de TI/CE

Benefícios
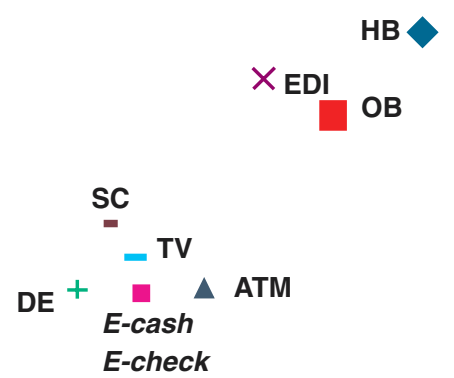

Valores

Fonte: Albertin (1997) 
As aplicações de TI, tradicional e de CE, são consideradas importantes fontes de informações sobre os clientes dos bancos, os quais utilizam essas informações para o estabelecimento de perfil de cliente, o desenvolvimento de produtos e serviços etc. A possibilidade de utilizar a integração eletrônica para a customização em massa é considerada um potencial a ser explorado no futuro, devido ao fato de que a utilização de TI/CE ainda está num estágio inicial e, portanto, muitos dos conceitos e aspectos ainda precisam ser mais bem estudados e tratados. Um dos sinais mais significativos dessa situação é a prioridade das aplicações de TI/CE que têm grande similaridade com as de TI tradicional e o fato de que elas são tidas principalmente como novos canais de vendas de produtos já existentes, e não para o desenvolvimento de novos produtos e serviços.

Outra contribuição dessas aplicações, considerada pelos bancos, é o seu poder na divulgação de produtos e serviços bancários, devido à facilidade de incluir novas funcionalidades e ao número crescente de clientes que as utiliza, permitindo, assim, um acesso mais fácil dos clientes aos produtos e serviços. Esses também são os motivos de os bancos considerarem essas aplicações com grande potencial como novo canal de vendas, principalmente para aqueles clientes que procuram formas de evitar sua presença física nas agências.

Essas aplicações de TI/CE também são consideradas de grande potencial para a identificação de novos produtos e serviços, devido ao seu poder de mudança no relacionamento com os clientes e à sua facilidade de desenvolvimento e acesso a partir da infra-estrutura existente. Da mesma forma, elas tendem a diminuir o tempo de comercialização desses novos produtos e, assim, permitir um serviço melhor aos clientes.

Os bancos, de uma maneira geral, têm buscado identificar novas oportunidades de negócio, porém existem diferenças nas suas diretrizes organizacionais. Alguns procuram identificar oportunidades por meio da aplicação de tecnologia de forma direta no seu negócio, enquanto outros procuram também oportunidades de diversificação, por exemplo, por meio de parcerias para a prestação de serviços on-line ou outra utilização de TI/CE, como a intermediação eletrônica. Os bancos também estão atentos ao surgimento de concorrência de participantes de outros setores.

Além disso, eles têm considerado a hipótese de criar ou participar da criação de shopping centers virtuais, sendo que há indícios de sua efetivação. As discussões sobre esse tema sempre têm como base a participação em um ambiente no qual os outros participantes, consumidores e fornecedores, teriam de ser clientes de um só banco, ou seja, as transações financei- ras seriam predominantemente internas ao banco.

As aplicações de TI/CE oferecem grandes contribuições por meio de economia direta, desde o aumento de produtividade até a viabilização de atendimento a um número muito elevado de clientes e transações, principalmente as de home banking e office banking. Essa contribuição está relacionada ao fato de que os custos das transações nesse ambiente são significativamente menores do que na forma tradicional. Os bancos consideram a TI como uma das mais importantes áreas a continuar recebendo grandes volumes de investimento, não representando o maior custo nem comprometendo a estratégia de competitividade e globalização dos bancos.

Atualmente, as aplicações de $e$-cash e $e$ check são as que apresentam maior necessidade de aprendizagem tecnológica, devido à falta de definição e potencial de mudança nos processos de negócio. As demais aplicações já foram objeto de aprendizagem por meio das TIs tradicionais; no entanto estas ainda requerem esforços para uma melhor adequação dos sistemas de retaguarda.

Os bancos consideram que algumas das aplicações de TI/CE são fortemente facilitadas e apoiadas pela infra-estrutura pública aberta, como a Internet. Esse tipo de infra-estrutura, porém, não é considerado estrategicamente conveniente para outras aplicações, como a rede de ATMs, que é utilizada como diferenciação competitiva.

\section{AMBIENTE EMPRESARIAL E COMÉRCIO ELETRÔNICO NO SETOR BANCÁRIO}

$\mathrm{O}$ ambiente empresarial tem vivenciado várias mudanças nos últimos anos, as quais têm definido novos contornos para os vários setores da economia e seus relacionamentos internos e externos, inclusive com os clientes e os consumidores.

O ambiente empresarial atual, por um lado, tem exigido que a TI ofereça soluções e suporte para as suas novas necessidades e, por outro lado, exige a identificação e o aproveitamento de novas oportunidades que a TI oferece. O CE pode ser considerado um dos seus grandes facilitadores e viabilizadores do novo ambiente empresarial. 
Uma das importantes características do novo ambiente empresarial é a globalização, que também tem sido significativa no setor bancário, desde a entrada de concorrentes estrangeiros no mercado nacional e a entrada de instituições nacionais no mercado internacional até a realização de parte de seus processos em localidades diferentes.

O CE é considerado uma forma efetiva de estar presente em outros mercados, assim como de aumentar sua presença no
O CE no setor bancário oferece grandes oportunidades e um caminho bastante promissor para as organizações que souberem aproveitar seu potencial de forma inovadora e ágil. mercado nacional. O mesmo tem acontecido com as organizações estrangeiras em relação ao nosso mercado. Nesse cenário, uma das questões que estão sendo debatidas refere-se ao fato de que o investimento que está sendo realizado em TI/CE tende a aumentar os custos dos bancos nacionais, que já são considerados mais elevados que os de seus concorrentes estrangeiros.

Os bancos estudados consideram que a TI, seja a tradicional ou a de $\mathrm{CE}$, não representa o maior componente de seus custos e que existem outras áreas de custo que, se necessário e sempre que possível, deverão ser reduzidas, como pessoal e obtenção de recursos financeiros. Para os bancos, a TI/CE representa uma poderosa e promissora arma competitiva que deve continuar a receber significativos investimentos, devendo contribuir para a redução de custo, para a flexibilidade e a agilidade em outras áreas, aumentando, assim, o poder competitivo dos bancos.

Os bancos são considerados as organizações que tradicionalmente realizam grandes investimentos em TI e têm seus processos, produtos e serviços fundamentalmente apoiados por essa tecnologia. Isso tem permitido que os bancos também sejam vistos como organizações que estão se preparando e contribuindo para o surgimento de uma economia digital.

Argumenta-se que a utilização de TI, no princípio, foi justificada pela necessidade de atender a um número bastante significativo de clientes e de produtos e serviços e pela necessidade de redução de custo. Atualmente, essa utilização é justificada pela me- lhoria de qualidade permitida em relação aos produtos e serviços e, conseqüentemente, no atendimento aos clientes. Finalmente, a TI/CE é justificada como a maneira de os bancos nacionais tornarem-se mais competitivos e entrarem nesse ambiente de economia digital, o qual eles acreditam ser não uma promessa, mas uma realidade.

Os bancos consideram que, com o surgimento e a efetivação dos mercados eletrônicos, os seus clientes terão cada vez mais ofertas de melhores produtos e serviços, bem como facilidades de escolha de seus fornecedores financeiros. Assim, os bancos têm procurado utilizar a infra-estrutura existente e as que estão sendo criadas para oferecer acesso a seus produtos e serviços sem limite de localização e tempo, de forma mais fácil e a um custo mais baixo.

Acredita-se que os bancos que não considerarem o mercado eletrônico e não aderirem a ele efetivamente tendem a ter seus mercados radicalmente reduzidos ou eliminados. Além disso, os bancos consideram que somente aqueles com grande poder de investimento deverão efetivamente utilizar todo o potencial do mercado eletrônico. Os bancos estudados consideram que no seu segmento, grandes bancos nacionais de varejo, não haverá grandes ameaças de pequenas instituições poderem passar a competir com eles viabilizadas pela TI/CE.

Os bancos têm efetivado a integração eletrônica, desde a utilização de TI tradicional até a atual utilização de TI/CE, buscando redução de custo, melhoria de processo, novos papéis nos processos de negócio e exploração de novas oportunidades. No entanto, os bancos têm tradicionalmente restringido a integração eletrônica, realizando-a somente com seus clientes, pessoa física ou jurídica; por exemplo, os bancos têm permitido que seus clientes troquem informações financeiras de forma eletrônica para pagamento somente a organizações que também sejam clientes do banco. Quando a transação inclui organizações que não são clientes, o pagamento é realizado por meio de DOCs e câmaras de compensação. Essa postura é evidenciada pelo fato de os bancos não planejarem a utilização de $e$-cash e $e$-check em curto ou médio prazos ou a participação em shopping centers virtuais.

O estabelecimento de padrões para a integração eletrônica é considerado importante pelos bancos, que também consideram difícil o estabelecimento de um padrão único a ser adotado de forma completa por todas as organizações. Os bancos tendem a continuar utilizando adaptações e complementações aos padrões estabelecidos, não acreditando que mesmo uma associação possa estabelecer um padrão único. 
O mesmo acontece em relação à criação de uma infra-estrutura totalmente pública. Os bancos consideram importante a sua criação e utilizam a existente, como no caso da Internet, mas dificilmente permitirão a utilização de sua própria infra-estrutura por outras organizações ou seus clientes ou mesmo promoverão a integração de suas redes às redes de outras organizações. Essa posição é baseada no argumento de que a infra-estrutura de cada banco é seu diferencial estratégico.

Um dos usos potenciais da integração eletrônica pelos bancos, a ser explorado no futuro, é a integração com outros serviços, com os bancos se tornando provedores de integração com outros serviços. Isso exigirá algum tipo de padronização da infra-estrutura e dos sistemas dos vários participantes.

Finalmente, num ambiente com concorrência crescente, o CE faz parte das estratégias dos bancos, mudando não a importância ou efetividade, mas apenas a agilidade e rapidez em adotá-lo, além, obviamente, do alinhamento com as estratégias e a cultura dos bancos. A postura estratégica dos bancos em relação ao CE vai desde o pioneirismo e a exploração mais agressiva dessa imagem, juntamente com seu potencial na melhoria da qualidade do atendimento a clientes e processos internos, até uma postura voltada para uma assimilação mais lenta dessa tecnologia e menor velocidade no desenvolvimento e implementação de suas aplicações.

Outro aspecto estratégico que diferencia os bancos é a postura em relação ao aproveitamento de oportunidades de negócio que não estão intimamente ligadas ao negócio bancário, como a exploração de oportunidades surgidas com a integração ou a intermediação eletrônica, por meio de parcerias e novas empresas. Essa diferença de postura influencia diretamente a ex- ploração das aplicações de TI/CE pelos bancos, sendo que os bancos que buscam novas oportunidades tendem a ter uma postura mais agressiva na utilização dessa tecnologia, mesmo que restrita a seus próprios clientes e redes.

Outra característica está relacionada à quantidade de planejamento em relação à implementação de aplicações de TI/CE. Alguns bancos tendem a diminuir o esforço de planejamento e aumentar de forma controlada o risco na utilização mais rápida dessas aplicações, enquanto outros tendem a ser mais avessos a riscos, aumentando os esforços de planejamento e retardando a utilização dessas aplicações.

\section{CONCLUSÃO}

Os bancos estão dedicando significativo esforço organizacional e realizando grandes investimentos no $\mathrm{CE}$, mas as aplicações que estão sendo desenvolvidas e implementadas têm uma sólida base nas aplicações de TI tradicional. As facilidades guardam uma grande similaridade em relação àquelas já oferecidas pelos bancos por meio das aplicações existentes.

O CE é considerado um grande potencial para novas estratégias e oportunidades de negócio, tanto em nível interno dos bancos, com redução de custo e melhoria de processos, como no relacionamento com clientes com novos canais de vendas, novos produtos e serviços e novas formas de relacionamento e até mesmo em novas oportunidades em novos escopos de negócio. Assim, o aumento da complexidade do $\mathrm{CE}$, e conseqüentemente das organizações que o adotam, deve significar mais oportunidade do que risco.

O Quadro 3 apresenta a relação das aplicações de TI/CE para o setor bancário, relacionando o ní-

Quadro 3 - Nível de utilização e estimativa para implementação das aplicações de TI/CE

\begin{tabular}{ccc}
\hline Aplicações de TI/CE & Nível de utilização & Estimativa para implementação \\
\hline Home banking & Intenso & Atual \\
DOC eletrônico & Baixo & Atual \\
Office banking & Intenso & Curto prazo \\
EDI & Moderado & Curto prazo \\
Smart card & Baixo & Curto prazo \\
ATM & Baixo & Médio prazo \\
E-cash & Muito baixo & Médio prazo \\
E-check & Muito baixo & Longo prazo \\
TV a cabo & Baixo & Longo prazo \\
\hline
\end{tabular}

Fonte: Albertin (1997). 
vel de utilização que os bancos pretendem atingir e a estimativa dos prazos de sua implementação. $\mathrm{O}$ nível de utilização refere-se à quantidade de produtos e serviços bancários a serem atendidos pelas respectivas aplicações.

As estimativas apresentadas no Quadro 3 consideram, de forma geral, a previsão de implementação das funcionalidades básicas de cada aplicação de TI/CE, lembrando que o pioneirismo é tido como importante na estratégia competitiva
O CE faz parte das estratégias dos bancos, mudando não a importância ou efetividade, mas apenas a agilidade e rapidez em adotá-lo, além, obviamente, do alinhamento com as estratégias e a cultura dos bancos. dos bancos. A análise das informações para a elaboração da estimativa também considerou a importância das funcionalidades em alguns poucos produtos e serviços.

Uma das principais características da atual utilização de TI/CE está relacionada à integração e comunicação eletrônica dos bancos com seus próprios clientes, sendo que praticamente ainda não existem aplicações efetivas ou, pelo menos, não há planejamento formal ou divulgação de informações que integrem os bancos e as organizações dos vários setores num ambiente totalmente eletrônico, aberto e de fácil acesso.

A utilização de infra-estrutura aberta e pública, como a Internet, tem permitido disponibilizar os produtos e serviços bancários de forma fácil e barata para os clientes dos bancos ou para aqueles que se tornem seus clientes.

A integração eletrônica dos bancos ou fornecedores de outros serviços ainda é baixa. Essa situação não permite que os bancos sejam considerados uma das partes totalmente inseridas no mercado eletrônico, nem que atuem como provedores de acesso a outros fornecedores ou como intermediários eletrônicos. Entretanto, os bancos têm realizado discussões internas para a participação em um ambiente de compras eletrônicas ou o seu desenvolvimento.

As tecnologias mais inovadoras, sob o ponto de vista de sistemas eletrônicos de pagamento, ainda são consideradas objeto de estudo e aproveitamento futuro, o que é coerente com a postura atual dos bancos, mas restritivo em relação a novas oportunidades e ao amplo desenvolvimento de uma economia digital.

As principais razões dadas pelos bancos para essa situação são a segurança e sua estratégia competitiva. A segurança está relacionada com o risco potencial que um ambiente totalmente eletrônico e aberto representa para as instituições bancárias; assim, os bancos limitam as suas aplicações para as transações entre seus próprios clientes. A estratégia competitiva, relativa à utilização de TI, é fortemente baseada na convicção de que as soluções e infra-estrutura próprias ainda são um diferencial importante e representam fortes barreiras a novos entrantes.

A situação atual das aplicações de TI/CE nos bancos pode ser definida como um estágio ainda inicial de sua utilização, mas é um indício claro de que o caminho realmente é o do CE. Como conclusão, pode-se afirmar que, exatamente por estar num estágio inicial e com uma aplicação ainda restrita, o CE no setor bancário oferece grandes oportunidades e um caminho bastante promissor para as organizações que souberem aproveitar seu potencial de forma inovadora e ágil. $\bigcirc$

REFERÊNCIAS BIBLIOGRÁFICAS

ALBERTIN, A. L. Administração de informática e seus fatores críticos de sucesso: um estudo no setor bancário privado nacional. São Paulo, 1993. Dissertação (Mestrado) - Faculdade de Economia, Administração e Contabilidade (FEA), Universidade de São Paulo (USP).

ALBERTIN, A. L. Comércio eletrônico: um estudo no setor bancário. São Paulo, 1997. Tese (Doutorado) - Faculdade de Economia, Administração e Contabilidade (FEA), Universidade de São Paulo (USP).

ALBERTIN, A. L. Comércio eletrônico: benefícios e aspectos de sua aplicação. Revista de Administração de Empresas $R A E$, v.38, n.1, p.52-63, jan./mar. 1998.
APTE, U. et al. Reusability-based strategy for development of information systems: implementation experience of a bank. MIS Quarterly, v.14, n.4, p.420-33, Dec. 1990.

BALDWIN, C. Y. Debate: what is the future of banking? Harvard Business Review, v.68, n.4, p.144-61, July/Aug. 1991.

BLOCH, M., PIGNEUR, Y., SEGEV, A. On the road of electronic commerce: a business value framework, gaining competitive advantage and some research issue. Institut d'Informatique et Organisation, Ecole des Hautes Etudes Commerciales, Université de Lausanne, 1996.

CAMERON, D. Electronic commerce: the new business platform of the Internet. Charleston: Computer Technology Research Corp., 1997.
CONNOLY, D. W. An evaluation of the World Wide Web as a platform for electronic commerce. In: KALAKOTA, R., WHINSTON, A. B. (Eds.). Readings in electronic commerce. New York: Addison-Wesley, 1997.

CRANE, D. B., BODIE, Z. Form follows function: the transformation of banking. Harvard Business Review, v.74, n.2, p.109-17, Mar./Apr. 1996.

KALAKOTA, R., WHINSTON, A. Frontiers of electronic commerce. New York: Addison-Wesley, 1996.

KALAKOTA, R., WHINSTON, A. Electronic commerce: a manager's guide. New York: Addison-Wesley, 1997. 